ORIGINAL ARTICLE

\title{
Motor vehicle driver injury and marital status: a cohort study with prospective and retrospective driver injuries
}

\author{
G Whitlock, R Norton, T Clark, R Jackson, S MacMahon
}

Injury Prevention 2004;10:33-36. doi: 10.1136/ip.2003.003020

See end of article for authors' affiliations

.....................

Correspondence to: Dr G Whitlock, Clinical Trial Service Unit and Epidemiology Studies Unit, Harkness Building, Radcliffe Infirmary, Oxford OX2 6HE, UK; gary.whitlock@ ctsu.ox.ac.uk

\begin{abstract}
Objective: To investigate the association of marital status with risk of motor vehicle driver injury. Design: A cohort study with prospective and retrospective outcomes. Setting: New Zealand.

Participants: A total of 10525 adults (a volunteer sample of a multi-industry workforce, $\mathrm{n}=8008$; and a random sample of urban electoral rolls, $\mathrm{n}=2517$ ).

Exposure variable: Self reported marital status, assessed from a questionnaire administered in 1992-93 (baseline).

Main outcome measure: Motor vehicle driver injury resulting in admission of the driver to hospital and/or the driver's death, during the period 1988-98; hospitalisation and mortality data were obtained by record linkage to national health databases.

Results: During 108741 person-years of follow up, 139 driver injury cases occurred (85 before baseline, 54 after). After adjustment for age, sex, and study cohort, never married participants had twice the risk of driver injury (hazard ratio [HR] 2.06,95\% confidence interval [CI] 1.35 to 3.16 ) as married participants (HR 1.00). The relative risk for never married participants was slightly higher (HR 2.29), though less precise $(95 \% \mathrm{Cl} 1.39$ to 3.76 ), after further adjustment for alcohol intake, driving exposure, area of residence, body mass index, and occupational status.

Conclusions: After taking age, sex, and other variables into account, never married people had a substantially higher risk of driver injury than married people. While requiring corroboration, these findings imply that it may be appropriate for driver injury countermeasures to be targeted to never married people.
\end{abstract}

l: $\mathrm{t}$ makes sense for certain road safety interventions to be targeted to drivers because drivers are very probably responsible for a high proportion of road fatalities and injuries, not only among themselves but among other road users. Such targeting could potentially be improved by better knowledge of the characteristics of drivers at increased risk of motor vehicle crashes. One easily measured and plausibly relevant, but little investigated, characteristic of drivers is their marital status. There is some evidence that single people take more risks while driving than married people, ${ }^{1-3}$ but direct evidence concerning their risks of driver injury is sparse. A small number of observational studies have reported higher risks of total vehicle related fatality among single people, ${ }^{4-8}$ but few have specifically addressed this question with respect to driver injury (including to driver fatality). ${ }^{10}$ Moreover, the determinants of driver injury cannot necessarily be inferred from the determinants of a composite outcome such as total vehicle related fatality, as quite plausibly the associations with other components of the composite outcome (for example, passenger injury, cyclist injury, or pedestrian injury) might differ in strength, or perhaps even direction, from the associations with driver injury. Such differences could be expected, for example, if single people tend to walk or cycle more than married people. If single people do in reality have independently increased risks of driver injury, then it should be possible to implement driver injury countermeasures that not only target young adults and men, for example, but also drivers of any age or sex who happen to be single. As the epidemiological evidence for or against such an approach is still sketchy, we investigated the association of marital status with risk of driver injury in the Fletcher Challenge-University of Auckland Heart and Health Study, a New Zealand cohort study designed to investigate determinants of injury and chronic disease in a population of 10525 adults. ${ }^{11-13}$

\section{METHODS}

\section{Participants}

Participants in this cohort study were recruited in 1992-93 (baseline) from two sources: the workforce of a nationwide multi-industry corporation (8008 participants, response rate $76 \%)$ and the electoral rolls of greater Auckland (2517 participants, response rate $67 \%$ ). The ages at baseline ranged from 16 to 88 years (median 42 years). Seventy two percent of participants were men. All participants provided signed consent to take part in the study, and the study was approved by the University of Auckland Human Subjects Ethics Committee.

\section{Exposure}

Data on marital status were obtained from information reported by participants in a questionnaire at baseline. Participants were asked, "What is your marital status?", and they were provided four possible answers: "single", "married or living with a partner", "separated or divorced", and "widowed". For the purpose of these analyses, the first two categories are termed "never married" and "married", respectively, and the last two categories (which were combined into a single category) are termed "separated, divorced, or widowed".

Abbreviations: $\mathrm{Cl}$, confidence interval; $\mathrm{HR}$, hazard ratio 


\section{Potential confounders}

Driving exposure was estimated from two sources: age specific and sex specific data on driving exposure in the 1989-90 New Zealand Household Travel Survey, ${ }^{14}$ and self reported occupation (which was classified as likely to involve much, some, little or no driving). Age, sex, alcohol intake (self reported maximum daily intake), and area of residence (population >200 000, $20000-200000$, or <20 000) were based on data reported by participants in the baseline questionnaire. Occupational status was defined as the International Socioeconomic Index score ${ }^{13}{ }^{15}$ for self reported occupation. Body mass index $\left(\mathrm{kg} / \mathrm{m}^{2}\right)$ was calculated from height and weight as measured by research nurses at baseline.

\section{Outcome}

Participants were classified as cases if they had been injured between 1988 and 1998 while driving a motor vehicle, and the injury resulted in the hospitalisation and/or death of the driver. Data on deaths and hospitalisations were obtained by record linkage to national databases maintained by the New Zealand Ministry of Health. In New Zealand, most non-fatal injuries severe enough to require hospital inpatient treatment result in admission to a public hospital, ${ }^{16}$ and all public hospitals compulsorily provide the Ministry of Health with summary information on each inpatient admission. All cases had an International Classification of Diseases, 9th revision, $\mathrm{N}$ code in the range 800-999, an E code in the range 810-829, and evidence that they had been driving at the time of the crash (either a free text narrative description indicating this, or an $\mathrm{E}$ code fourth digit of 0 or 2 ).

\section{Statistical methods}

Hazard ratios (HR) and 95\% confidence intervals (CI), which are for the "total" follow up period (that is, the prospective and retrospective periods combined) unless stated otherwise, were estimated using Cox proportional hazards models (PHREG in SAS, release 8.00). The time origin was specified as 1 January 1988, and follow up was terminated at the date of driver injury, date of death (from any cause) or 31 December 1998, whichever occurred first. Hazard ratios were adjusted for covariates by inserting continuous (age and occupational status) or categorical (all other covariates) terms for these variables into the Cox models. Categorical covariates were used for alcohol intake, driving exposure, and body mass index ${ }^{12}$ because of evidence that associations between these variables and risk of the outcome were not log linear. The proportional hazards assumption was tested by fitting time dependent covariates.

\section{RESULTS}

During a mean 10.3 years of follow up (108 741 personyears), 139 incident driver injury cases (137 non-fatal and two fatal) occurred. Eighty five cases occurred retrospectively (that is, before baseline), and 54 prospectively (that is, after). Just over half $(n=46)$ of the cases in the retrospective period, and two thirds $(\mathrm{n}=37)$ in the prospective period, were injured while driving a four wheeled vehicle (in most instances, a car). The remainder in each period were injured while driving a motorcycle.

The distributions of various known or possible driver injury risk factors across categories of marital status are shown in table 1. Married participants were disproportionately more likely to be men, resident in rural areas, and members of the workforce cohort. In addition, they tended to have higher occupational status, body mass index, and estimated driving exposure. Heavy drinking of alcohol was more common among never married participants. On average divorced, separated, and widowed participants were 10 years older than married participants, and 24 years older than never married participants.

The crude driver injury incident rate for never married participants was about three times that for married participants (table 2). After adjustment for age, sex and study cohort, never married participants were still about twice as likely (HR 2.06, 95\% CI 1.35 to 3.16) as married participants to have experienced a driver injury during follow up. The hazard ratio was slightly higher (HR 2.29), though less precise (95\% CI 1.39 to 3.76), after further adjustment for alcohol intake, driving exposure, area of residence, body mass index, and occupational status.

There were too few divorced, separated, or widowed cases (12) to detect any plausibly higher or lower risks in this group (table 2). Additionally, when stratifying by follow up period or type of vehicle driven, the hazard ratios in each exposure category were very imprecise. Nonetheless, the results were still broadly compatible with increased risks of driver injury among never married people in both the prospective (HR $2.01,95 \%$ CI 0.99 to 4.06 ) and retrospective (HR $2.11,95 \%$ CI 1.23 to 3.61 ) periods, and for both motorcycle (HR 1.52, 95\% CI 0.84 to 2.77 ) and four wheeled vehicle (HR 2.32, 95\% CI 1.20 to 4.46 ) driver injury.

\section{DISCUSSION}

After taking age and sex into account, the risk of driver injury in this cohort study was about twice as high for never married people as for married people. This result is qualitatively consistent with previous reports-based on case series, ${ }^{4-6} 8$ a cross sectional study, ${ }^{17}$ and a case-control study ${ }^{7}$ —of increased risks of vehicle $\mathrm{crash}^{17}$ or vehicle related fatality ${ }^{4-8}$ among single people. But the present report extends beyond these findings to show that never married people specifically had increased risks of driver injury.

We know of just three previous observational studies (all case-control studies) of the association between marital status and either driver injury ${ }^{10}$ or driver crashes. ${ }^{18}$ Two of these reported higher risks among non-married or single people, ${ }^{90}$ while the other found no evidence of an association $^{18}$ (though this study involved just 98 cases, and so might have had insufficient statistical power to detect an association of plausible strength). The two studies that found an association excluded as cases those drivers who were judged (by the police, ${ }^{9}$ or by an unspecified source ${ }^{10}$ ) to have not been responsible for the crash. However, the validity of such judgments is uncertain. Most crashes have multiple contributory causes, so driver responsibility must in reality exist on a continuum, and it is not clear what objective criteria could be used to sensibly divide this continuum into the categories "responsible" and "not responsible". Moreover, in a high proportion of crashes the full circumstances would not have been known, so in many cases it would not have been possible, even theoretically, to determine the level of crash responsibility.

The increased risk of driver injury among never married people in the present study appears unlikely to be accounted for by chance (the association was highly statistically significant), driver injury affecting marital status (the quantitatively similar associations in the prospective and retrospective periods suggests that this may have been negligible), or outcome misclassification (a postal survey of 179 motor vehicle injury cases and a random sample of 200 other participants showed 95\% [95\% CI $89 \%$ to $100 \%$ ] sensitivity and $97 \%$ [95\% CI $94 \%$ to $100 \%$ ] specificity for driver injury detection). Furthermore, losses to follow up (estimated from Statistics New Zealand data on emigration and international travel as $4 \%-5 \%$ of the total available person-years of follow up), or violation of the proportional hazards assumption (lowest $\mathrm{p}$ value for time dependent 
Table 1 Standardised distributions* of several known or possible risk factors for driver injury, by marital status

\begin{tabular}{|c|c|c|c|c|}
\hline & Never married & Married & $\begin{array}{l}\text { Divorced, separated, } \\
\text { widowed }\end{array}$ & $\begin{array}{l}\text { p Value for } \\
\text { homogeneity }\end{array}$ \\
\hline Number of participants $\dagger$ & 1481 & 7766 & 1240 & \\
\hline Age, mean (SD), years $\ddagger$ & $30.7(13.9)$ & $44.9(15.3)$ & $55.4(13.6)$ & $<0.0001$ \\
\hline Men, \%§ & 67.2 & 75.7 & 53.0 & $<0.0001$ \\
\hline $\begin{array}{l}\text { Maximum alcohol intake, } \\
\text { mean (SD), drinks/day }\end{array}$ & $8.4(7.6)$ & $5.8(7.9)$ & $7.5(7.3)$ & $<0.0001$ \\
\hline $\begin{array}{l}\text { Total estimated driving } \\
\text { exposure, mean (SD), } 000 \\
\mathrm{~km} \|\end{array}$ & $103(44)$ & $115(44)$ & $76.2(44)$ & $<0.0001$ \\
\hline $\begin{array}{l}\text { Much work related driving, } \\
\% \S\end{array}$ & 2.9 & 2.5 & 3.0 & 0.45 \\
\hline Resident in rural area, \% & 15.4 & 21.4 & 17.2 & $<0.0001$ \\
\hline $\begin{array}{l}\text { Occupational status score, } \\
\text { mean (SD)† }\end{array}$ & 43.1 (17.5) & $46.9(18.3)$ & 43.7 (17.3) & $<0.0001$ \\
\hline $\begin{array}{l}\text { Body mass index, mean } \\
\text { (SD), } \mathrm{kg} / \mathrm{m}^{2}\end{array}$ & $25.3(4.5)$ & $26.2(4.6)$ & $25.8(4.3)$ & $<0.0001$ \\
\hline Workforce cohort, \% & 75.0 & 76.9 & 72.1 & $<0.0001$ \\
\hline
\end{tabular}

*Percentages, means, and $\mathrm{p}$ values adjusted (unless stated otherwise) for age and sex by direct standardisation to the study population (categorical variables), or by analysis of covariance (continuous variables). $p$ Values calculated by the Mantel-Haenszel $\chi^{2}$ test for association (categorical variables) or analysis of covariance (continuous variables).

†Data on marital status missing for 38 participants.

¥Standardised for sex only.

§Standardised for age only (in the case of work related driving, additional standardisation for sex was not possible because of sparse data).

$\|$ Total estimated driving exposure between 1988 and 1998; not standardised for either age or sex since this variable was estimated from age and sex.

covariates $=0.77$ ), seem unlikely to have accounted for the observed association. However, the association could potentially have been biased to some extent by misclassification of marital status, and by errors in the measurement of driving exposure, which are each discussed below.

\section{Misclassification of marital status}

Marital status will have been misclassified somewhat since it tends to change with time. Assessing marital status in the middle of the follow up period (as opposed to the start or end) should have mitigated this problem to some extent. Nonetheless, if $10 \%$ of the retrospective cases had married just before baseline, such that they were classified as married but had in fact spent most of the retrospective period as (say) never married, then the crude incidence rate ratio for never married people in this period would have been underestimated by $22 \%$. On the other hand, if $10 \%$ of the prospective cases who reported at baseline that they were never married then married soon after baseline, the crude incidence rate ratio for never married people in this period would have been overestimated by about $17 \%$. Thus, these plausible secular changes in marital status ( $1 \%$ to $2 \%$ of the
New Zealand adult population marries each year ${ }^{19}$ ) would probably have had opposing effects on the period specific hazard ratios, and these effects may have tended to cancel each other out in estimation of the hazard ratios for the total follow up period.

\section{Driving exposure}

Driving exposure was measured only crudely in this study, so the possibility that the observed association was partly or wholly accounted for by differences in driving exposure cannot be ruled out. Yet while it is not possible to say that never married people had increased risks per kilometre driven, it is possible to say that they had increased risks per unit time of follow up, which in itself could be potentially useful information for deciding how to target driver injury countermeasures.

\section{Risk taking behaviours}

If the observed association between marital status and driver injury risk was causal, it might reflect a generally greater willingness by single people to take risks while driving. This tendency has been observed for some established risk factors

Table 2 Incidence rates and hazard ratios for driver injury, by indicators of socioeconomic status

\begin{tabular}{|c|c|c|c|c|c|c|}
\hline \multirow[b]{2}{*}{ Marital status } & \multirow[b]{2}{*}{$\begin{array}{l}\text { No of } \\
\text { cases }\end{array}$} & \multirow[b]{2}{*}{$\begin{array}{l}\text { Person- } \\
\text { years }\end{array}$} & \multirow[b]{2}{*}{ Incidence rate* } & \multicolumn{3}{|c|}{ Hazard ratio $(95 \% \mathrm{Cl})$, Adjusted for: $\dagger$} \\
\hline & & & & Age, sex, cohort & $\begin{array}{l}\text { Age, sex, cohort, alcohol } \\
\text { intake, driving exposure }\end{array}$ & $\begin{array}{l}\text { Age, sex, cohort, alcohol intake, } \\
\text { driving exposure, area of residence, } \\
\text { BMlł, occupational status }\end{array}$ \\
\hline Never married & 45 & 15154 & 29.7 & $2.06(1.35$ to 3.16$)$ & $2.17(1.32$ to 3.56$) \S$ & 2.29 (1.39 to 3.76$)$ \\
\hline Married & 78 & 80446 & 9.7 & 1.00 (reference) & 1.00 (reference) & 1.00 (reference) \\
\hline $\begin{array}{l}\text { Divorced, separated, } \\
\text { widowed }\end{array}$ & 12 & 12768 & 9.4 & $1.63(0.88$ to 3.01$)$ & $1.67(0.87$ to 3.21$)$ & $1.72(0.88$ to 3.33$)$ \\
\hline Missing & 4 & 373 & 107.2 & & & \\
\hline
\end{tabular}




\section{Key points}

- There is little reliable evidence about whether single people and married people have importantly different risks of motor vehicle driver injury.

- The determinants of driver injury are of particular interest since drivers frequently injure other road users.

- In this cohort study, never married people had twice the risk of serious driver injury as married people (after taking factors such as age and sex into account).

- It might be useful to target some driver injury countermeasures specifically to single people.

for vehicle related fatality, including drink driving ${ }^{1}$ and not using a seatbelt. ${ }^{1-3}$ While adjustment for usual alcohol intake did not importantly attenuate the hazard ratio for never married people in this study (see table 2 footnote), this observation does not preclude the possibility that alcohol intake was a causal factor since maximum daily alcohol intake would have been an imperfect proxy for drink driving.

\section{Implications}

These findings imply that previous reports of higher risks of vehicle related injury among never married people reflect, at least in part, higher risks of driver injury. While still requiring corroboration, these findings suggest that it might be appropriate for driver injury countermeasures to be targeted not only to men and young adults, for example, but specifically also to never married people.

\section{ACKNOWLEDGEMENTS}

Gary Whitlock undertook this research during the tenure of a Health Research Council of New Zealand training fellowship. The research was supported in part by grants from the Fletcher Challenge Welfare Fund, the Health Research Council of New Zealand, and the National Heart Foundation of New Zealand. Taane Clark is supported by a National Health Service (UK) research training fellowship.

\section{Authors' affiliations}

G Whitlock, Clinical Trials Research Unit, University of Auckland, New Zealand
R Norton, S MacMahon, Institute for International Health, University of Sydney, Australia

T Clark, Centre for Statistics in Medicine, University of Oxford, United Kingdom

R Jackson, Department of Community Health, University of Auckland, New Zealand

\section{REFERENCES}

1 West GB, Moskal PD, Dzuiban CD, et al. Gender and marital differences for risk taking among undergraduates. Psychol Rep 1996;78:315-20.

2 Morelock S, Hingson RW, Smith RA, et al. Mandatory seatbelt law support and opposition in New England-a survey. Public Health Rep 1985; 100:357-63.

3 Hersch J. Smoking, seat belts, and other risky consumer decisions: differences by gender and race. Managerial and Decision Economics 1996;17:471-81.

4 Berkson J. Mortality and marital status: reflections on the derivation of etiology from statistics. Am J Public Health 1962;52:1318-29.

5 Gove WR. Sex, marital status, and mortality. American Journal of Sociology 1973;79:45-67.

6 Koskenvuo M, Sarna S, Kaprio J, et al. Cause-specific mortality by marital status and social class in Finland during 1969-1971. Soc Sci Med 1979;13A:691-7.

7 Barreto SM, Swerdlow AJ, Smith PG, et al. Risk of death from motor-vehicle injury in Brazilian steelworkers: a nested case-control study. Int J Epidemiol 1997;26:814-21.

8 Burgoa M, Regidor E, Rodriguez C, et al. Mortality by cause of death and marital status in Spain. Eur J Public Health 1998;8:37-42.

9 McCarroll JR, Haddon W. A controlled study of fatal automobile accidents in New York City. J Chron Dis 1962;15:811-26.

10 Böhning D, Suksawasdi Na Ayutha R. A case-control study of non-fatal traffic accidents on hospital patients in Bangkok metropolis. Soz Praventivmed 1997:42:351-7.

11 MacMahon S, Norton R, Jackson R, et al. Fletcher Challenge-University of Auckland Heart and Health Study: design and baseline findings. NZ Med J 1995; 108:499-502.

12 Whitlock G, Norton R, Clark T, et al. Is body mass index a risk factor for motor vehicle driver injury? A cohort study with prospective and retrospective injuries. Int J Epidemiol 2003;32:147-9.

13 Whitlock G, Norton R, Clark T, et al. Motor vehicle driver injury and socioeconomic status: a cohort study with prospective and retrospective driver injuries. J Epidemiol Community Health 2003;57:512-6.

14 Ministry of Transport. New Zealand household travel survey: July 1989-June 1990. Wellington: Traffic Research and Statistics Section, Land Transport Division, Ministry of Transport, 1990.

15 Ganzeboom HB, Treiman DJ. Internationally comparable methods of occupational status for the 1988 international standard classification of occupations. Soc Sci Res 1996;25:201-9.

16 Langley JD. Experiences using New Zealand's hospital based surveillance system for injury prevention research. Methods Inf Med 1994;34:340-4.

17 Hamed MM, Katamine NM, Armouti AK. Traffic accidents frequency and the human factor. Journal of Traffic Medicine 1994;22:53-9.

18 Alparslan B, Dereboy C, Öner Savk S, et al. The relationship of traffic accidents with personality traits. Journal of Traffic Medicine 1999;27:25-30.

19 Statistics New Zealand. Marriage and divorce in New Zealand (March 2001). Wellington, Statistics New Zealand, 2001 (www.statistics.govt.nz). 